\title{
Tau Gene Expression in Rat Sensory Neurons during Development and Regeneration
}

\author{
Monica M. Oblinger, ${ }^{1}$ Alexandra Argasinski, ${ }^{1}$ Johnson Wong, ${ }^{1}$ and Kenneth S. Kosik ${ }^{2}$ \\ 'Department of Cell Biology and Anatomy, Chicago Medical School, North Chicago, Illinois 60064 and ${ }^{2}$ Department of \\ Neurology (Neuroscience), Harvard Medical School and Center for Neurologic Diseases, Department of Medicine \\ (Division of Neurology), Brigham and Women's Hospital, Boston, Massachusetts 02115
}

In the mature rat dorsal root ganglion (DRG), only one tau isoform is expressed, and this protein (110 kDa in apparent molecular weight) is considerably larger in size than the predominant tau isoforms found in brain. The size of the mRNA encoding the "big" tau mRNA in DRG [ $\approx 8$ kilobases (kb)] is also much larger than that of the major rat brain tau mRNA species $(\approx 6 \mathrm{~kb})$. In this study, we examined the pattern of normal developmental changes in expression of this high-molecular-weight (HMW) tau and its encoding mRNA and also determined how axonal injury of adult DRG neurons effected the expression of this gene. RNA blotting experiments revealed that higher levels of HMW tau mRNA were present in the DRG at early postnatal times than in the adult. Immunoblotting of total DRG protein using a monclonal tau antibody revealed that the immature DRG (7 d postnatal) contained a 62-kDa tau isoform in addition to the HMW tau isoform that was expressed in the adult DRG. Neither of the tau isoforms expressed in the immature DRG was present to any significant extent in either immature or adult rat brain. To examine how tau expression changed in adult DRG neurons during regeneration, the sciatic nerves of rats were unilaterally crushed, and the L4 and L5 DRG were harvested 1,7 , and $14 d$ later. Immunoblotting studies revealed that the levels of HMW tau protein decreased in the DRG following axotomy, with the largest reduction occurring at $7 \mathrm{~d}$ postinjury. Notably, the tau isoform pattern did not change in axotomized adult neurons. That is, the 62-kDa tau isoform that was prominent in the immature DRG did not reappear in axotomized adult neurons. Northern blot analysis of total RNA from axotomized adult DRG showed a reduction in the levels of HMW tau mRNA (8-kb species) from 1 to 28 d postaxotomy. At these same postaxotomy times, the levels of $\beta$-tubulin mRNA were dramatically increased. Results of RNA blotting studies were confirmed by quantitative in situ hybridization of DRG neurons with a ${ }^{35}$ S-labeled tau CDNA probe. Analysis of the autoradiograms showed a significant decrease in the levels of tau mRNA in the large-sized $(>1000$ $\mu \mathrm{m}^{2}$ ) DRG neurons at $7 \mathrm{~d}$ postaxotomy. These findings of

We gratefully acknowledge the excellent technical help of Judy Pickett in these studies. We thank Skip Binder for providing the tau-1 antibody. This work was supported by NIH Grants NS-21571 to M.M.O. and AG06601 and AG06172 to K.S.K.

Correspondence should be addressed to Dr. Monica M. Oblinger, Department of Cell Biology and Anatomy, Chicago Medical School, 3333 Green Bay Road, North Chicago, IL 60064.

Copyright (C) 1991 Society for Neuroscience $0270-6474 / 91 / 112453-07 \$ 03.00 / 0$
}

downregulated expression of HMW tau protein and its mRNA in axotomized DRG cells that are undergoing regeneration suggest that this tau isoform may endow the axonal cytoskeleton with properties that are less than optimal for axonal growth. For example, if this tau form has a significant role in stabilizing the axonal cytoskeleton, the downregulation of HMW tau during regeneration would generate greater plasticity in the cytoskeleton of regenerating neurons.

Neuronal microtubules play a central role in axonal growth and development by providing a structural framework for new axons and by serving as substrates for membrane vesicle transport in the axon. Many of the properties of neuronal microtubules are modulated by microtubule-associated proteins (MAPs) of either the high-molccular-weight (HMW) MAP or the tau protein class (reviewed in Matus, 1988). For example, tau proteins can promote microtubule assembly by initiating microtubule growth (Cleveland et al., 1977) and can stabilize microtubules against depolymerization (Drubin and Kirschner, 1986). In the mature mammalian brain, the major tau protein species range in size from 50 to $70 \mathrm{kDa}$ (Cleveland et al., 1977). A larger-sized variant of tau had been reported in certain cells, including mature dorsal root ganglion (DRG), sympathetic neurons, and PC12 cells (Drubin et al., 1984a, 1986, 1988; Peng et al., 1986a,b). Our studies have indicated that this larger tau isoform $(110 \mathrm{kDa}$ in apparent size) appears to be the only tau species present in DRG and peripheral nerve. We will refer to this tau isoform as HMW tau. While information about the properties of brain tau has accumulated, almost no attention has been given to the HMW tau variant of peripheral neurons.

In brain, the expression and activity of tau is known to change during development (Francon et al., 1982; Nunez, 1986). Tau proteins obtained from early postnatal rat brain present a simpler pattern on gels than does tau from adult brain. The immature brain tau proteins are a closely spaced doublet at 48 $\mathrm{kDa}$, while adult brain tau is considerably more heterogeneous, with at least three prominent doublets (Mareck et al., 1980; Francon et al., 1982). Interestingly, the microtubule assemblypromoting activity of immature brain tau is lower than that of adult brain tau (Mareck et al., 1980). Tau appears to be only a single gene (Drubin et al., 1984b; Neve et al., 1986) from which diversity is generated by both alternative splicing (Lee et al., 1988) and posttranslational modifications, such as phosphorylation (Lindwall and Cole, 1984). Recent studies have shown that immature brain tau protein contains three imperfectly repeated sequences that are putative microtubule-binding domains 
(Lee et al., 1989), while adult rat brain tau mRNA contains four such sequences (Kosik et al., 1989). This isoform switch from the three-repeat to the four-repeat form of tau during brain development has been proposed as a potential reason for the higher assembly-promoting ability of mature versus immature brain tau (Kosik et al., 1989). For the HMW tau present in the DRG and other peripheral neurons, information about changes in isoform patterns and functional propertics during development has not been available.

Studies of regenerating adult neurons have contributed to our understanding of the function of various other cytoskeletal proteins. Such studies have also shown that developmental patterns of cytoskeletal protein gene expression are often recapitulated during axonal regeneration in adult neurons (Hoffman and Cleveland, 1988). For example, the expression of certain tubulin mRNAs that are normally present at high levels only in immature neurons is selectively increased during axonal regeneration of adult DRG neurons (Hoffman and Cleveland, 1988; Miller et al., 1989). There is also a decrease in neurofilament (NF) protein mRNA levels in axotomized adult DRG neurons (Hoffman et al., 1987; Wong and Oblinger, 1987, 1990a,b) that parallels the low levels seen during early development (Julien et al., 1986; Schlaepfer and Bruce, 1990). During brain development, the levels of tau mRNA are known to be higher during early stages when axonal growth is occurring than in the adult (Couchie et al., 1988; Mangin et al., 1989). Virtually nothing is known about tau gene expression during axonal regeneration in adult mammals. We hypothesized that, if HMW tau was important for axonal growth, the pattern of tau expression during axonal regeneration of adult DRG neurons might revert to that seen during early development. To address this, we examined tau expression at both the protein and mRNA levels in adult rat DRG neurons during regeneration and compared this to the pattern of tau expression present in immature DRG neurons. We report here our findings that the expression of HMW tau in adult DRG neurons decreases following axotomy and that the isoform pattern remains adultlike. Thus, the developmental pattern of tau expression is not recapitulated by regenerating adult neurons.

\section{Materials and Methods}

Animals. Adult malc Spraguc-Dawley rats (Harlan Sprague Dawley, Indianapolis, IN) weighing $300-350 \mathrm{gm}$ as well as 7 -d-old postnatal (P7) rat pups were used in the experiments. All animals were acquired, cared for, and surgically handled in accordance with the guidelines specified in the NIH Guide for the Care and Use of Laboratory Animals. For surgical procedures, adult rats were anesthetized with a mixture of sodium pentobarbital $(27 \mathrm{mg} / \mathrm{kg})$ and chloral hydrate $(128 \mathrm{mg} / \mathrm{kg})$; for scheduled kills, rats were decapitated under ether anesthesia.

For axotomy studies, the sciatic nerves of adult rats were crushed unilaterally at the midthigh, 50-60 $\mathrm{mm}$ from the L5 DRG, by applying three successive 30-sec crushes with \#5 Dumont forceps as described previously (Wong and Oblinger, 1990a). Rats were killed 1, 7, 14, and $28 \mathrm{~d}$ after the axotomy, and the injured as well as the contralateral control side L4 and L5 DRG were rapidly removed. Normal control ganglia were obtained from untreated rats. For developmental studies, lumbar DRG were harvested from 7-d-old (P7) rat pups. Samples of cerebral cortex were harvested both from adult rats and from $\mathrm{P} 7$ rat pups. Tissue was frozen on powdered dry ice immediately after removal from the animals.

Immunoblotting. For each sample in the axotomy experiments, L4 and L5 DRG obtained from two or three different rats (four to six ganglia each for the axotomy and contralateral control conditions) were pooled. The experiments were repeated several times using three different pairs of pooled DRG samples at each postinjury time point $(1,7,14 \mathrm{~d})$. For the developmental studies, normal L4 and L5 DRG obtained from 25
P7 pups and from six normal adult rats were pooled and used as samples for gels. DRG were homogenized in ice-cold phosphate-buffered saline (PBS), and an aliquot of each sample was used to determine total protein by a standard Coomassie dye binding assay (Bradford, 1976). The remainder of the sample was mixed with an equal volume of BUST ( $2 \%$ $\beta$-mercaptoethanol, $8 \mathrm{M}$ urea, $1 \%$ SDS, $0.1 \mathrm{M}$ Tris, $\mathrm{pH} 6.8$ ) and stored at $-70^{\circ} \mathrm{C}$ until used for gel electrophoresis. Proteins were separated by SDS-PAGE on 1-mm-thick slab minigels consisting of a $10 \%$ acrylamide running gel with a $4 \%$ acrylamide stacking gel. Equal amounts of total protein from the various conditions $(20 \mu \mathrm{g}$ of DKG protein, $5 \mu \mathrm{g}$ of cortex samples) were loaded in the gel lanes. After electrophoresis, proteins were electrophoretically transferred to nitrocellulose (NC) as described previously (Oblinger, 1987), except that a mini-blotting apparatus (Bio Rad Laboratories) was used. The NC blots were incubated overnight at $4^{\circ} \mathrm{C}$ with a monoclonal antibody to tau (tau-1; Binder et al., 1985) at a 1:250 dilution, and the reactive bands were visualized using diaminobenzidine after the blots were incubated for $4 \mathrm{hr}$ at $4^{\circ} \mathrm{C}$ with a peroxidase-labeled rabbit anti-mouse secondary antibody (Boehringer Mannheim Biochemicals, Indianapolis, IN) at 1:300 dilution.

$R N A$ blots. DRG obtained from two or three different rats (typically four to six ganglia, including both L4 and L5) were pooled and used as samples for RNA blot studies. Both axotomized and contralateral control DRG samples were used. The experiments were replicated using two different pooled DRG samples (total of four to six rats) at each postinjury time point $(1,7,14,28 \mathrm{~d})$. For developmental studies, L4 and L5 DRG were obtained from four normal adult and 22 P7 rat pups. Total RNA was isolated from DRG as described (Chomcyznski and Sacchi, 1987), and $10 \mu \mathrm{g}$ RNA of each sample was separated by electrophoresis on $1 \%$ agarose gels in the presence of formaldehyde (Ausubel et al., 1987). The RNA was blotted onto Nytran membranes (Schleicher and Schuell) and baked at $80^{\circ} \mathrm{C}$ for $2 \mathrm{hr}$. The blots were hybridized with a "P-labcled tau cDNA probc (Kosik ct al., 1989) as described (Ausubcl et al., 1987) and washed to a final stringency of $0.1 \times$ SSC with $0.1 \%$ SDS at $50^{\circ} \mathrm{C}$. The blots were then stripped by immersion in boiling water for $5 \mathrm{~min}$ and then rehybridized with a ${ }^{32} \mathrm{P}$-labeled $\beta$-tubulin cDNA probe (RBT.1; Bond et al., 1984). The tubulin probe recognizes predominantly a 1.8 -kilobase $(\mathrm{kb})$ mRNA species in the DRG (Wong and Oblinger, 1990a). Autoradiographs were made by exposing Kodak XAR5 film to the blots for $1-2 \mathrm{~d}$.

In situ hybridization. Axotomized L4 and L5 DRG were harvested from three rats $7 \mathrm{~d}$ after sciatic nerve crush (total of six ganglia), and normal control DRG were obtained from four untreated rats (total of eight ganglia). The DRG were immediately fixed by immersion in $4 \%$ paraformaldehyde for $2 \mathrm{hr}$, embedded in paraffin, and then sectioned at $10 \mu \mathrm{m}$. The sections were hybridized with ${ }^{35} \mathrm{~S}$-labeled cDNA rat brain tau probe (Kosik et al., 1989) as described previously (Wong and Oblinger, 1987). After hybridization, sections were washed to a final stringency of $0.1 \times \mathrm{SSC}$ with $0.1 \% \mathrm{SDS}$ at $50^{\circ} \mathrm{C}$ for $15 \mathrm{~min}$ and then dehydrated through an increasing series of ethanol $/ 300 \mathrm{~mm}$ ammonium acetate. The sections were air dried, dipped into $37^{\circ} \mathrm{C}$ Kodak NTB2 emulsion (diluted 1:1 with $600 \mathrm{~mm}$ ammonium acetate), and stored at $4^{\circ} \mathrm{C}$ in the dark for $14 \mathrm{~d}$, after which they were developed and lightly counterstained with cresyl violet. The density of silver grains over largesized DRG neurons $\left(>1000 \mu \mathrm{m}^{2}\right)$ in which a clearly defined nucleus and nucleolus was present was determined using a computer-based image analysis system as described previously (Wong and Oblinger, 1987). Measurements of nonspecific background labeling were made from each section by determining the silver grain density over axonal regions of the DRG, and the neuronal grain counts from each section were corrected for such nonspecific labeling. From each DRG, grains counts from 25-50 different neurons were obtained. Mean grain density values were determined for the 7-d-postaxotomy and control groups by arithmetic averaging, and differences between groups were determined using an unpaired, two-tailed Student's $t$ test at the $95 \%$ confidence level.

\section{Results}

Developmental changes in neuronal tau expression

Immunoblotting was used to examine developmental changes in the expression of tau protein isoforms in both the rat DRG and brain (cerebral cortex). Major changes in the tau species expressed at early postnatal times (P7) and in the adult were observed in both regions (Fig. 1). The adult DRG contained a major immunoreactive tau protein that was considerably larger 

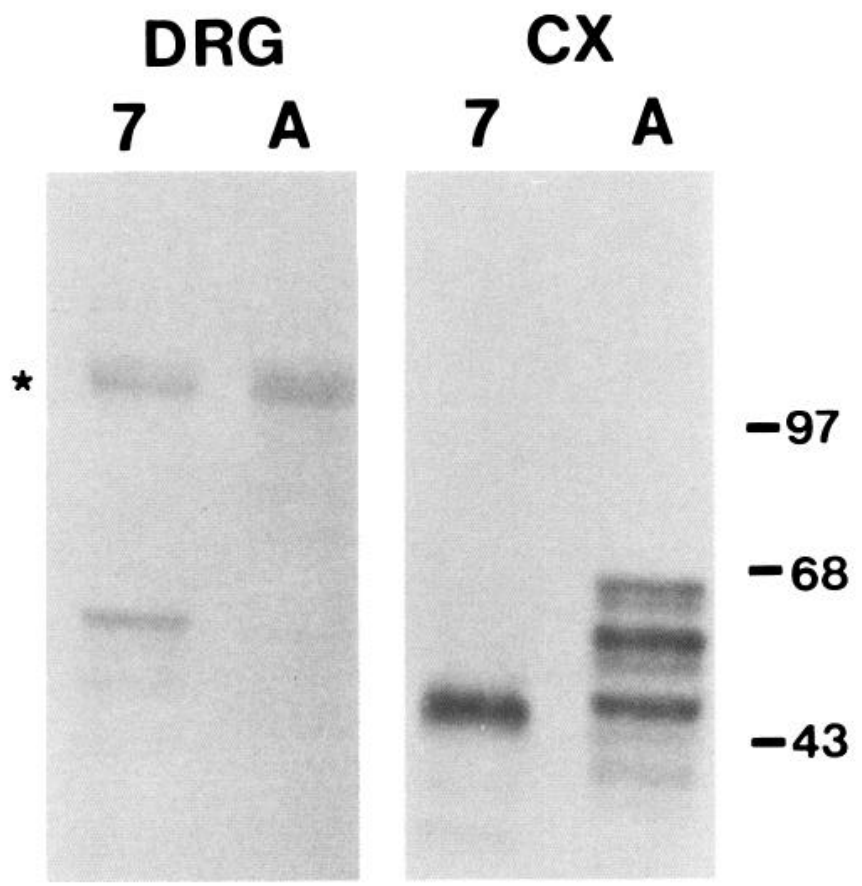

Figure 1. Immunoblot illustrating developmental changes in the expression of various tau protein isoforms in $D R G$ and cortex $(C X)$. Note that two main tau forms are present in the immature DRG (7), while only the $110-\mathrm{kDa}$ tau band $\left({ }^{*}\right)$ is present in the adult DRG $(A)$. In the neonatal cortex, only one tau species is present in the $50-\mathrm{kDa}$ region of the gel, while three prominent tau bands in the $50-70-\mathrm{kDa}$ region are present in adult cortex. Gel lanes were loaded with $20 \mu \mathrm{g}$ of total DRG protein and $5 \mu \mathrm{g}$ of total cortex protein. Molecular weight standards (in $\mathrm{kDa}$ ) are indicated on the right.

than the largest tau isoform present in adult cerebral cortex. The "big" or HMW tau species in the DRG was $110 \mathrm{kDa}$ in apparent molecular weight and was prominent in both the adult and P7 DRG samples (see Figs. 1, 3). Because the epitope recognized by the tau-1 antibody is known (Kosik et al., 1988), these experiments show that this portion of the sequence is present in HMW tau. In addition to the $110-\mathrm{kDa}$ tau, the P7 DRG also contained a second immunoreactive band at $62 \mathrm{kDa}$ (Fig. 1). In other experiments, additional minor immunoreactive tau bands, thought to be degradation products, were observed in both adult and P7 DRG samples (see Fig. 3).

The immunoblots consistently showed that the tau isoforms present in the DRG differed in their migration on SDS-PAGE from the tau isoforms present in samples of cortex (Fig. 1). This was true at both the adult and the P7 stage of development. In the adult rat cortex, three major immunoreactive tau bands and several minor bands were observed in the 50-70-kDa region, while in the P7 cortex a single major broad band, different in migration from any of adult brain tau forms, was found (Fig. 1). Relative to the DRG, the cortex samples contained far greater amounts of immunodetectable tau protein. This was evidenced by the fact that lower total protein loads from cortex $(5 \mu \mathrm{g})$ yielded more prominent immunoreactive bands than did considerably higher total protein loads $(20 \mu \mathrm{g})$ from the DRG (Fig. 1). Comparisons of relative levels of tau from $P 7$ to adult in both cortex and DRG were complicated by the isoform switches that occurred. However, it appeared that more HMW tau was present in the adult DRG than the P7 samples (see Figs. 1, 3).

Northern blotting demonstrated that the size of the tau mRNA

\section{DRG \\ CX \\ 7 A

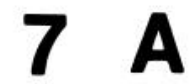

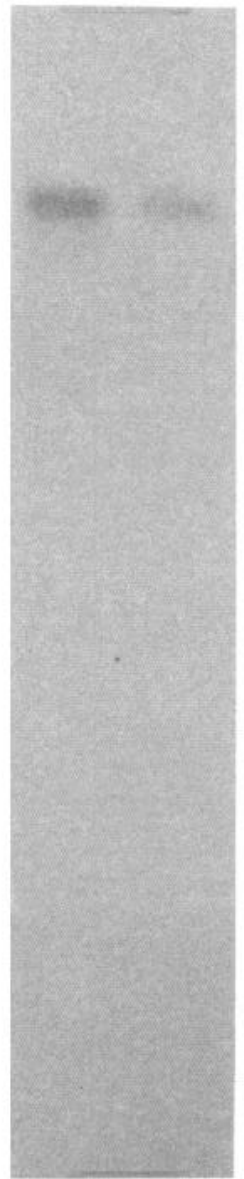

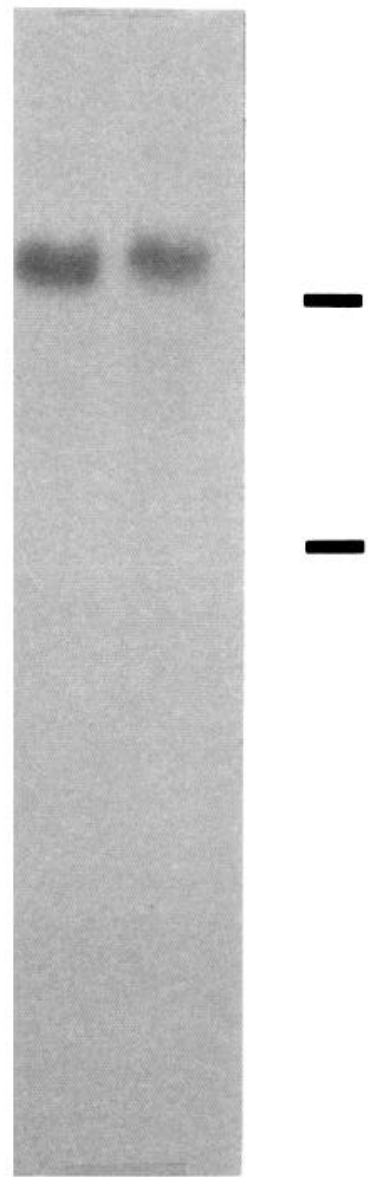

Figure 2. Northern blot illustrating developmental changes in tau mRNA levels in DRG and cortex. Equal amounts of total RNA $(20 \mu \mathrm{g})$ from $\mathrm{P} 7(7)$ and adult $(A) D R G$ and cortex $(C X)$ were hybridized with a ${ }^{32}$ P-labeled tau cDNA probe. Note that the size of the tau mRNA in cortex is smaller $(\approx 6 \mathrm{~kb})$ than that expressed in the DRG $(\approx 8 \mathrm{~kb})$. The autoradiographs also show that the level of tau mRNA is higher in both neonatal samples than in the adult samples. The positions of the $28 \mathrm{~S}$ and $18 \mathrm{~S}$ ribosomal markers are indicated by bars on the right.

species in DRG was considerably larger than the tau mRNA expressed in rat cortex. In both the P7 and adult DRG, a tau mRNA species that was approximately $8 \mathrm{~kb}$ in size was detected, while only an approximately 6-kb mRNA band was found in brain (Fig. 2). A slight but noticeable change in the migration of tau mRNA was observed in brain between P7 and adult samples, suggesting that a slightly different-sized tau message was expressed at these two stages (Fig. 2). RNA blotting experiments also showed that, in both DRG and cortex, higher levels of tau mRNA were present in the neonate than in the adult (Fig. 2). In each case shown in Figure 2, the gel lanes were loaded with equal amounts of total RNA from the different samples.

\section{Axotomy-induced changes in tau expression in DRG neurons}

The effect of axotomy on tau protein levels and on tau isoform expression in the adult DRG was examined by immunoblotting. 

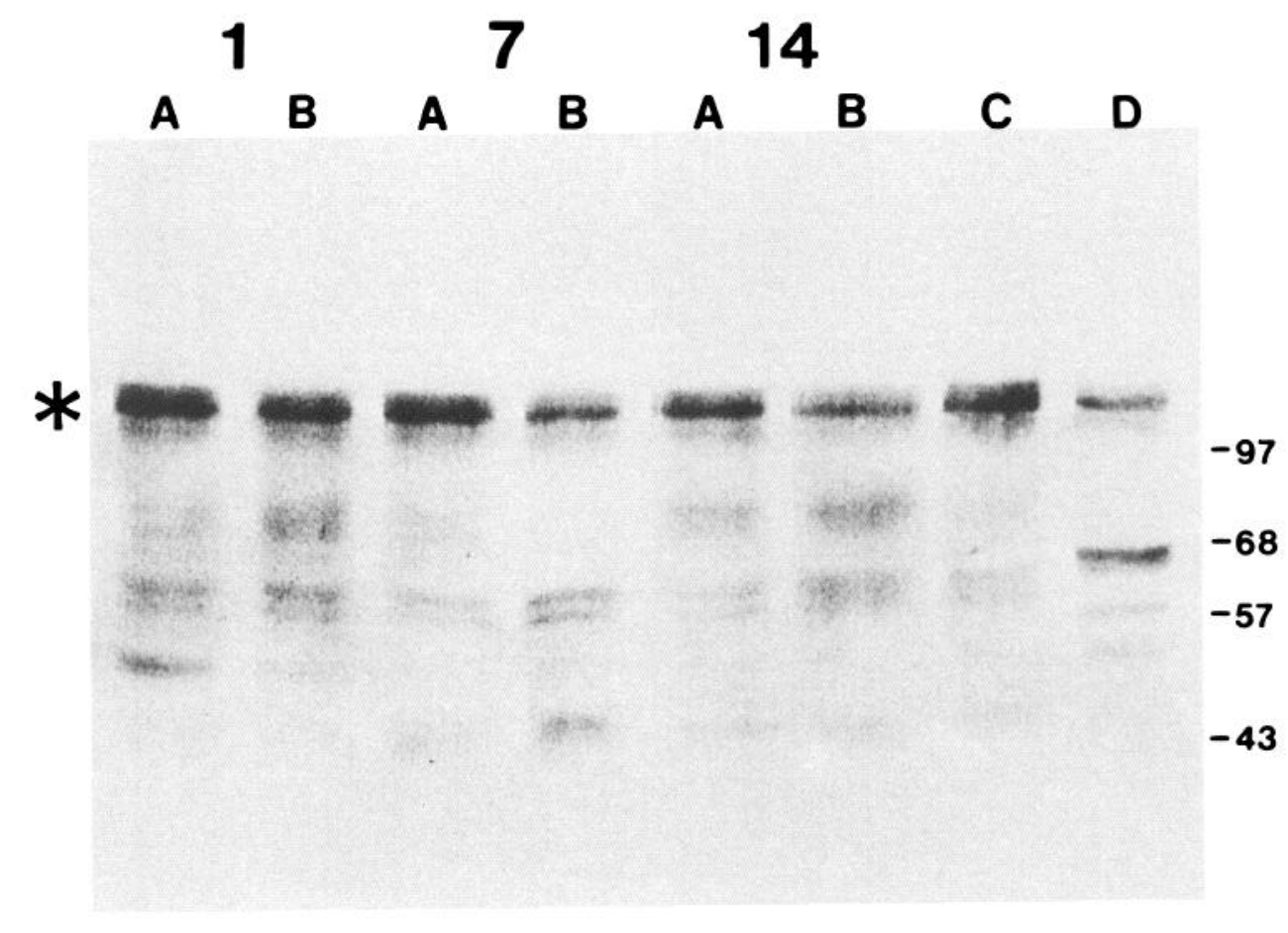

Figure 3. Immunoblot showing that tau protein levels decrease in the DRG after axotomy. All gel lanes were loaded with $20 \mu \mathrm{g}$ of total protein. Samples of contralateral control DRGs $(A)$ and axotomized DRGs $(B)$ at the indicated days $(1,7,14)$ after sciatic nerve crush are shown. Samples from normal, untreated adult DRGs $(C)$ and from normal baby (P7) DRGs $(D)$ are shown for comparison. The position of the 110$\mathrm{kDa}$ tau protein is indicated by the asterisk. Positions of molecular weight standards are shown on the right.

SDS gels were loaded with equal amounts of total adult DRG protein from different postinjury times, and the relative abundance of immunoreactive tau in the different samples was evaluated. Figure 3 illustrates a representative experiment that showed a reduction in the level of the HMW tau species in axotomized DRG. The level of tau protein in axotomized ganglia was consistently reduced at 7 and $14 \mathrm{~d}$ postaxotomy, but some variability existed in the apparent level of downregulation in different experiments. HMW tau levels in axotomized DRG at 7 and $14 \mathrm{~d}$ postinjury were lower than in paired contralateral control ganglia and in normal untreated DRG (Fig. 3). In no experiment was the smaller tau band $(62 \mathrm{kDa})$ that was prominent in the neonatal DRG observed in samples of axotomized adult DRG neurons (Fig. 3). This observation indicated that the axotomized adult DRG neuron did not begin to reexpress tau isoforms characteristic of earlier developmental stages. Rather, the level of expression of the adult HMW tau isoform was reduced in injured neurons.

Northern blotting of RNA samples from adult DRG from 128-d-postaxotomy times revealed that the levels of HMW tau mRNA were substantially decreased in axotomized DRG compared to control (Fig. 4A). The decrease was apparent as early as $1 \mathrm{~d}$ postaxotomy and appeared to be most pronounced at 7 $\mathrm{d}$ after injury. When the same blots were reprobed for class II $\beta$-tubulin mRNA, the opposite pattern was observed. That is, axotomized adult DRG exhibited a robust increase in the level of $\beta$-tubulin mRNA relative to control from 1 to $28 \mathrm{~d}$ after injury (Fig. $4 B$ ).

In situ hybridization of histological sections of normal adult DRG and $7 \mathrm{~d}$ postaxotomy adult DRG was done to confirm the changes observed in RNA blotting experiments and also to confirm that the observed downregulation of tau mRNA was a specific neuronal response. Autoradiograms of DRG sections hybridized with a ${ }^{35} \mathrm{~S}$-labeled tau cDNA probe revealed that the vast majority of label was located over neurons. A readily apparent difference in the degree of labeling of control and axotomized neurons at $7 \mathrm{~d}$ postinjury was observed (Fig. $5 A, B$ ). This difference was confirmed by quantifying the mean grain densities of control and axotomized DRG neurons using a computerassisted image analysis system. The mean grain density of axotomized large-sized DRG neurons was significantly less $(p<$ 0.05 ) than that of control neurons, indicating that a significant downregulation in tau mRNA levels had occurred in response to axotomy $7 \mathrm{~d}$ earlier (Fig. 5C).

\section{Discussion}

We have examined the expression of tau protein and its encoding mRNA during normal development and during regeneration of adult rat DRG neurons. The tau isoform expressed in the mature DRG has an apparent molecular mass of $110 \mathrm{kDa}$ and is distinct from the smaller tau proteins (50-70-kDa range) expressed in adult brain (cerebral cortex). We found that the immature DRG expressed a smaller tau isoform $(62 \mathrm{kDa})$ in addition to the HMW tau species. However, in both the immature and the mature DRG, only a single tau mRNA of 8-kb size was observed. N1 15 neuroblastoma cells have a single tau isoform that approximates the molecular mass of the HMW tau in DRG, and these cells also have a single tau mRNA of $8 \mathrm{~kb}$ (Drubin et al., 1984a, 1988). However, in PC1 2 cells, which express the HMW tau isoform in addition to the smaller $(50-70 \mathrm{kDa})$ tau proteins, mRNAs of both $6 \mathrm{~kb}$ and $8 \mathrm{~kb}$ have been described and are thought to code for the lower- and higher-molecularmass tau protein isoforms, respectively (Drubin et al., 1986, 1988). The two tau mRNAs are under differential regulation in PC1 2 cells, because the $8 \mathrm{~kb}$ mRNA is constitutively expressed, whereas the 6-kb tau mRNA is NGF induced (Drubin et al., 1988). The differential regulation of these isoforms in $\mathrm{PC} 12$ cells 


\section{AXOTOMY I CONTROL}

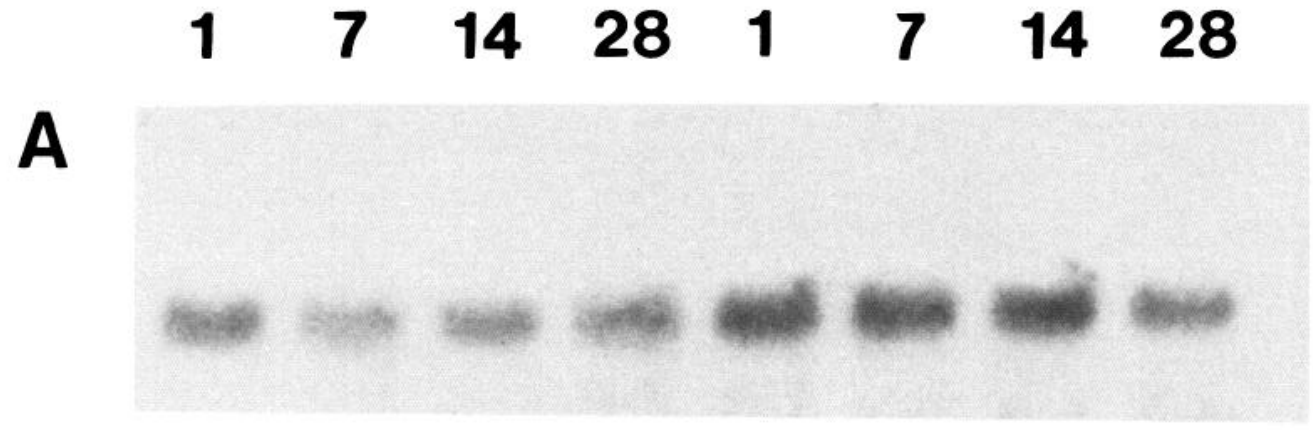

B
Figure 4. Northern blots illustrating axotomy-induced changes in the levels of tau and tubulin mRNAs in the DRG. Equal amounts of total RNA (10 $\mu \mathrm{g})$ from axotomized and contralateral control DRG at the indicated days after axotomy were blotted and hybridized sequentially with ${ }^{32} \mathrm{P}$-labeled cDNA probes to tau $(A)$ and $\beta$-tubulin $(B)$. Note that the levels of tau mRNA in the axotomized DRG are decreased relative to control at all postaxotomy times, while the $\beta$-tubulin mRNA levels are increased over control levels. is the principle argument that the HMW and smaller tau protein isoforms derive from distinct transcripts.

How tau isoform expression is regulated in the DRG is unknown, as is the actual molecular identity of the individual tau isoforms. The presence of only a single $8-\mathrm{kb}$ mRNA in both adult and immature DRG cells leaves open two alternative explanations for the origin of the two tau isoforms in the immature DRG. The transient expression of the 62-kDa DRG tau isoform relative to the $110-\mathrm{kDa}$ tau in the $\mathrm{DRG}$ during development may be due to developmentally timed expression of distinct (but similar $\approx 8$-kb size) mRNAs by differential splicing. Alternatively, it is possible that the smaller tau isoform present in the immature rat DRG is proteolytically generated from the larger form by the developmentally timed expression of a protease that generates the smaller isoform either in vivo or during homogenization.

From studies of rat brain tau, one site at which developmentally regulated splicing is known to take place is in the region of the repeated sequences (Kosik et al., 1989), where tau binds to the microtubule (Lee et al., 1989). In this region are four imperfectly repeated sequences of 31 amino acids each. The second repeat is under developmental regulation and is added in mature neurons. None of the sequences from the DRG, PC12, or N1 15 tau isoforms are published; however, preliminary polymerase chain reaction data from our laboratory suggests that PC12 cells with both large and small tau isoforms have predominantly, if not exclusively, the four-repeat form of tau (K. S. Kosik, unpublished observations). Whether or not a developmental shift in tau expression in the DRG includes splicing events within the microtubule-binding repeated sequences is presently unknown. Once the sequence of DRG tau is known, it may be possible to begin examining which exons are expressed at various developmental time points. Studies of DRG tau are ongoing to resolve this issue.
The results of the present study demonstrate that the levels of the HMW tau protein and its mRNA decrease in adult DRG neurons that have been axotomized and are undergoing regeneration. Interestingly, the $62-\mathrm{kDa}$ tau isoform is not reexpressed in adult DRG neurons during axonal regeneration. Thus, the pattern of tau expression in regenerating adult neurons is clearly distinct from the pattern of tau expression during DRG development. This finding thus challenges the idea that regeneration represents a simple recapitulation of development in terms of cytoskeletal gene expression. The recapitulation hypothesis had received considerable support from findings that regenerating adult DRG neurons revert to more immature patterns of expression of both NF and tubulin genes (Hoffman et al., 1987; Wong and Oblinger, 1987, 1990a,b; Hoffman and Cleveland, 1988; Oblinger et al., 1989; Miller et al., 1989). Our studies indicate that axonal outgrowth from adult neurons differs at least in some respect from the process that occurs during initial development.

What are some of the consequences of changes in HMW tau expression in regenerating DRG neurons? The answer to this question will require information about the functional attributes of the HMW tau protein, which at this point are largely unknown. However, based on the expression data obtained in this study, we might speculate that this tau isoform has more of a role in stabilizing the mature axonal cytoskeleton than it does in active axonal growth. The fact that the level of HMW tau protein is higher in the adult DRG than in the neonate is consistent with this possibility because the adult axonal cytoskeleton is widely considered to be a somewhat less dynamic entity than that of the developing neuron. It should be noted, however, that direct evidence for changes in the dynamic properties of the cytoskeleton, such as changes in microtubule solubility or tubulin assembly/disassembly kinetics during development of sensory neurons and their axons, has not yet been obtained. 

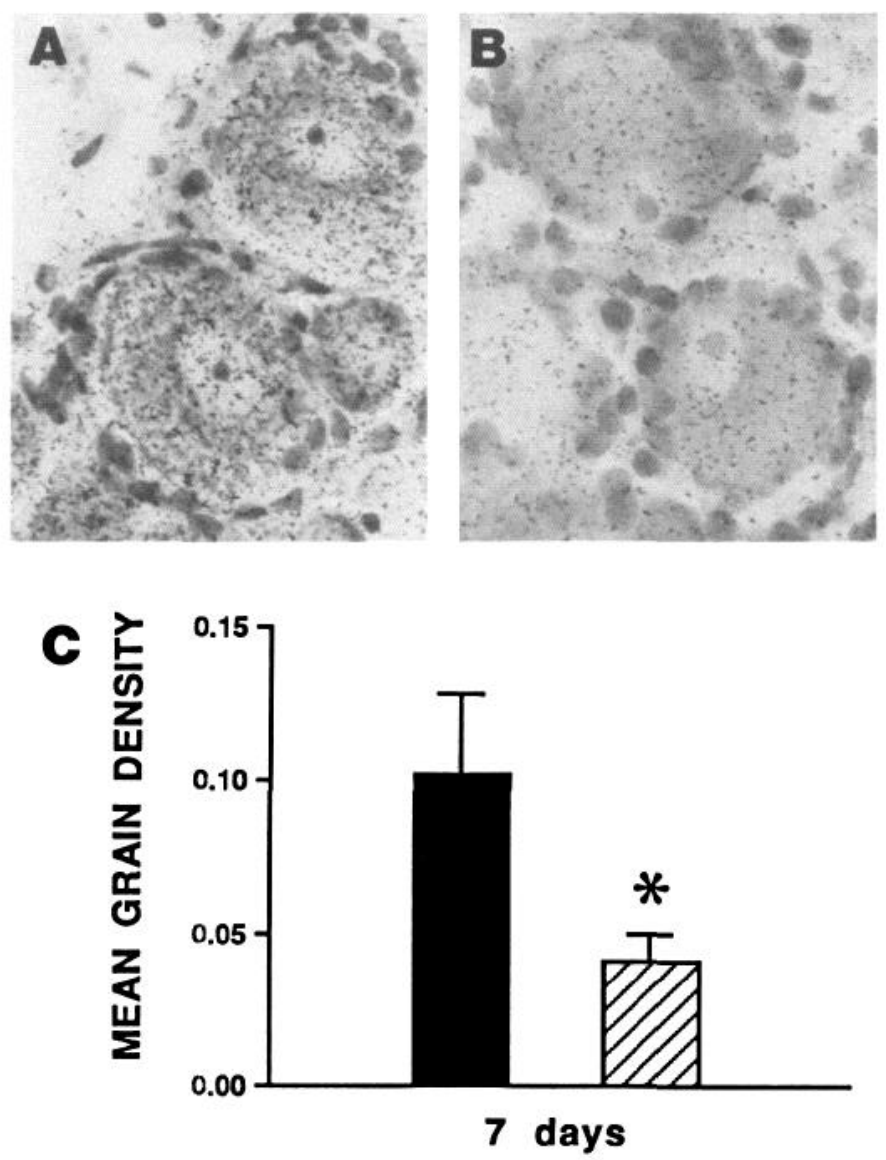

Figures 5. In situ hybridization of DRG neurons using ${ }^{35} \mathrm{~S}$-labeled tau cDNA probe. The autoradiograms of normal $(A)$ and axotomized $(B)$ L5 DRG neurons (7 d after sciatic nerve crush) show reduced labeling of axotomized neurons relative to controls. $C$, Quantification of the mean grain densities over large-sized, normal control DRG neurons (solid bar) and axotomized DRG neurons (hatched bar) confirmed that tau mRNA levels were downregulated $7 \mathrm{~d}$ after axotomy. Average grain densities (number of grains $/ \mu \mathrm{m}^{2}$ ) and SEM are plotted. The asterisk indicates a significant difference between the two means $(p<0.05)$.

Because the neonatal DRG expresses a smaller, 62-kDa tau form in addition to HMW tau, it may be that it is this lower- $M_{r}$ tau form that is important for axonal growth, at least during development. Thus, in the absence of a reappearance of the immature DRG tau form $(62 \mathrm{kDa})$ during regeneration in the adult, downregulation of the HMW tau may be a "fall-back" mechanism by which DRG cells can modulate the properties of the neuronal cytoskeleton away from stability and towards greater plasticity.

MAPs are known to affect microtubule dynamics in vitro, and the microtubule-stabilizing properties of tau have been shown in a variety of ways. For example, microinjection of tau into fibroblasts, which normally contain no native tau protein, promotes the in vivo polymerization of microtubules and stabilizes microtubules such that the rate of microtubule depolymerization is markedly decreased (Drubin and Kirschner, 1986). Downregulation of tau in conjunction with upregulation of tubulin in regenerating neurons (Hoffman and Cleveland, 1988; Wong and Oblinger, 1990a) may affect the assembly/disassembly dynamics of the microtubule system in these neurons. Recent studies have shown that microtubules in lamprey anterior bulbar cells are destabilized following axotomy (Hall et al., 1991).
Future studies will determine if similar events occur in mammalian neurons and their axons during regeneration.

Recent studies have underlined the important role of the lowmolecular-weight tau proteins in neurite formation. For example, when cultured neurons are treated with antisense tau oligonucleotides to block tau synthesis, axonlike neurites fail to develop (Caceres and Kosik, 1990). In addition, the expression of brain tau in non-neural cells that do not normally express tau can give rise to the formation of neuritelike processes (Kosik et al., 1990). The role of HMW tau remains quite unexplored at the present time. However, the present study suggests that HMW tau may have a more important role in stabilizing the neuronal cytoskeleton than it does in active neurite growth. Because this isoform appears to be the only tau species that is present in the PNS, further studies of this isoform may provide insight into the potentially unique role(s) of this protein in the nervous system.

\section{References}

Ausbel R, Brent R, Kingston RE, Moore DD, Seidman JG, Smith JA, Struhl K (1987) Current protocols in molecular biology, pp. 4.9.14.9.5. New York: Greene and Wiley.

Binder LI, Frankfurter A, Rebhun LI (1985) The distribution of tau in the mammalian central nervous system. J Cell Biol 101:13711378.

Bond JF, Robinson GS, Farmer SR (1984) Differential expression of two neural cell specific $\beta$-tubulin mRNAs during rat brain development. Mol Cell Biol 4:1313-1319.

Bradford MM (1976) A rapid and sensitive method for the quantitation of microgram quantities of protein utilizing the principle of protein-dye binding. Anal Biochem 72:248-254.

Caceres A, Kosik KS (1990) Inhibition of neurite polarity by tau antisense oligonucleotides in primary cerebellar neurons. Nature 343: $461-463$.

Chomcyznski P, Sacchi N (1987) Single-step method of RNA isolation by acid guanidinium thiocyanate-phenol-chloroform extraction. Anal Biochem 162:156-159.

Cleveland DW, Hwo S, Kirschner MW (1977) Purification of tau, a microtubule-associated protein that induces assembly of microtubules from purified tubulin. J Mol Biol 116:207-225.

Couchie D, Charriere-Bertrand D, Nunez J (1988) Expression of the mRNA for tau proteins during brain development and in cultured neurons and astroglial cells. J Neurochem 50:1894-1899.

Drubin DG, Kirschner MW (1986) Tau protein function in living cells. J Cell Biol 103:2739-2746.

Drubin DG, Kirschner MW, Feinstein S (1984a) Microtubule-associated tau protein induction by nerve growth factor during neurite outgrowth in PC12 cells. In: Molecular biology of the cytoskeleton (Borisy GG, Cleveland DW, Murphy DB, eds), pp 343-355. Cold Spring Harbor NY: Cold Spring Harbor Laboratory.

Drubin DG, Caput D, Kirschner MW (1984b) Studies on the expression of the microtubule associated protein, tau, during mouse brain development, with newly isolated complementary DNA probes. J Cell Biol 98:1090-1097.

Drubin DG, Kobayashi S, Kirschner MW (1986) Association of tau protein with microtubules in living cells. Ann NY Acad Sci 466:257268.

Drubin DG, Kobayashi S, Kellog D, Kirschner MW (1988) Regulation of microtubule protein levels during cellular morphogenesis in nerve growth factor-treated PC12 cells. J Cell Biol 106:1583-1591.

Francon J, Lennon AM, Fellous A, Mareck A, Pierre PN, Nunez J (1982) Heterogeneity of microtubule associated proteins and brain development. Eur J Biochem 129:465-471.

Hall GS, Lee VM-Y, Kosik KS (1991) Microtubule destabilization and neurofilament phosphorylation precede dendritic sprouting following close axotomy of lamprey central neurons. Proc Natl Acad Sci USA, in press.

Hoffman PN, Cleveland DW (1988) Neurofilament and tubulin expression recapitulates the developmental program during axonal regeneration: induction of a specific $\beta$-tubulin isotype. Proc Natl Acad Sci USA 85:4530-4533. 
Hoffman PN, Cleveland DW, Griffin JW, Landes PW, Cowan NJ, Price DL (1987) Neurofilament gene expression: a major determinant of axonal caliber. Proc Natl Acad Sci USA 84:3472-3476.

Julien J-P, Meyer D, Flavel D, Hurst J, Grosveld F (1986) Cloning and developmental expression of the murine neurofilament gene family. Mol Brain Res 1:243-250.

Kosik KS, Orecchio LD, Binder LI, Trojanowski J, Lee VM-Y (1988) Epitopes that span the tau molecule are shared with neurofibrillary tangles. Neuron 1:817-825.

Kosik KS, Orecchio LD, Bakalis S, Neve RL (1989) Developmentally regulated expression of specific tau sequences. Neuron 2:1389-1397.

Kosik KS, Caceres A, Pardee J, Cohen-Gould L, Knops J, McConlogue $\mathrm{L}$ (1990) A role for tau in neural morphogenesis. J Cell Biol 111: $436 \mathrm{a}$.

Lee G, Cowan NJ, Kirschner MW (1988) The primary structure and heterogeneity of tau protein from mouse brain. Science 239:285-288.

Lee G, Neve RL, Kosik KS (1989) The microtubule binding domain of tau protein. Neuron 2:1615-1624.

Lindwall G, Cole RD (1984) Phosphorylation affects the ability of tau protein to promote microtubule assembly. J Biol Chem 259:53015305.

Mangin GD, Couchie DC, Charriere-Bertrand C, Nunez J (1989) Timing of expression of tau and its encoding mRNAs in the developing cerebral neocortex and cerebellum of the mouse. J Neurochem 53: 45-50.

Mareck A, Fellous I, Francon J, Nunez J (1980) Changes in composition and activity of microtubule-associated proteins during brain development. Nature 284:353-355.

Matus A (1988) Microtubule-associated proteins: their potential role in determining neuronal morphology. Annu Rev Neurosci 1 1:29-44.

Miller FD, Tetzlaff W, Bisby MA, Fawcett JW, Milner RJ (1989) Rap- id induction of the major embryonic alpha-tubulin mRNA T $\alpha 1$, during nerve regeneration in adult rats. J Neurosci 9:1452-1463.

Neve RL, Hanis P, Kosik KS, Kurnik DM, Donlon TA (1986) Identification of cDNA clones for the human microtubule-associated protein tau and chromosomal localization of the genes for tau and microtubule-associated protein 2. Mol Brain Res 1:271-280.

Nunez J (1986) Differential expression of distinct microtubule-associated proteins during brain development. Dev Neurosci 8:125-141.

Oblinger MM (1987) Characterization of post-translational processing of the high molecular weight neurofilament protein in vivo. J Neurosci 7:2510-2521.

Oblinger MM, Szumlas RA, Wong J, Liuzzi FJ (1989) Changes in cytoskeletal gene expression affect the composition of regenerating axonal sprouts elaborated by dorsal root ganglion neurons in vivo. J Neurosci 9:2645-2653.

Peng I, Binder LI, Black MM (1986a) Cultured neurons contain a variety of microtubule-associated proteins. Brain Res 361:200-211.

Peng I, Binder LI, Black MM (1986b) Biochemical and immunological analyses of cytoskeletal domains of neurons. J Cell Biol 102:252-262.

Schlaepfer WW, Bruce J (1990) Simultaneous up-regulation of neurofilament proteins during the postnatal development of the rat nervous system. J Neurosci Res 25:39-49.

Wong J, Oblinger MM (1987) Changes in neurofilament gene expression occur after axotomy of dorsal root ganglion neurons: an in situ hybridization study. Metab Brain Dis 2:291-303.

Wong J, Oblinger MM (1990a) A comparison of peripheral and central axotomy effects on neurofilament and tubulin gene expression in rat dorsal root ganglion neurons. J Neurosci 10:2215-2222.

Wong J, Oblinger MM (1990b) Differential regulation of peripherin and neurofilament gene expression in regenerating rat DRG neurons. J Neurosci Res 27:332-341. 